\title{
OASIS: clinical audit in a tertiary care centre
}

\author{
Sruthy Soman, Sobha S. Nair*, Janani J. N., \\ Radhamany K., Ann John Kurien
}

Department of Obstetrics and Gynecology, Amrita Institute of Medical Sciences, Kochi, Kerala, India

Received: 22 February 2018

Accepted: 28 March 2018

\section{*Correspondence:}

Dr. Sobha S. Nair,

E-mail: drsobhasnair@gmail.com

Copyright: (C) the author(s), publisher and licensee Medip Academy. This is an open-access article distributed under the terms of the Creative Commons Attribution Non-Commercial License, which permits unrestricted non-commercial use, distribution, and reproduction in any medium, provided the original work is properly cited.

\section{ABSTRACT}

Background: Obstetric anal sphincter injury involves injury to the anal sphincter and rectal mucosa sustained at time of vaginal delivery and can result in significant long-term morbidity. These injuries have been defined as $3^{\text {rd }}$ and $4^{\text {th }}$ degree lacerations that involve disruption of the anal sphincter and rectal mucosa respectively. Objectives of this study were to find out the incidence of obstetrical anal sphincter injuries, to identify the risk factors for of OASIS and the outcome of primary repair in terms of anal incontinence and its associated complications.

Methods: We did a descriptive study of OASIS by retrospective analysis of the labour case records. The study period was 1 year between August 2016 to July 2017. Inclusion criteria were singleton pregnancy, vertex presentation, instrumental and normal vaginal delivery. Exclusion criteria were multiple pregnancy, non-vertex presentation and caesarean section. Proforma was developed to capture the age, parity, gestational age in weeks, induction of labour, epidural analgesia, delivery duration, type of episiotomy, instrumentation, shoulder dystocia, occipito posterior position,manual support, weight of the baby, suturing method. Postnatal evaluation after 6 weeks and 6 months for perineal discomfort, pain, incontinence, wound infection, breakdown, fistula were noted.

Results: The incidence of OASIS was $1.4 \% .81 .8 \%$ women had $3^{\text {rd }}$ degree perineal and $18.1 \%$ had $4^{\text {th }}$ degree perineal tear. The mean age of the patients were 27.9 years, gestational age of 39.45 weeks, $72.7 \%$ were primiparous. Induction of labour with prostaglandins was done in $36.36 \%$ and Pitocin augmentation for $81.81 \%$. The duration of second $36.36 \%$ had $60-89 \mathrm{~min}$ and $27.27 \%$ had duration more than $90 \mathrm{~min}$. $54.54 \%$ had epidural analgesia, $36.36 \%$ had shoulder dystocia, $36.36 \%$ had instrumental delivery. $72.72 \%$ babies had birth weight between 3-3.5 kg, 9\% between $3.5-4 \mathrm{~kg}$. Ano vaginal fistula developed in $9 \%$.

Conclusions: Appropriate training, anticipating and identifying major degrees of perineal tear helps in reducing the complications. Anovaginal fistula is distressing and disabling the patient and to her near ones.

Keywords: Ano vaginal fistula, OASIS, Perinealtear

\section{INTRODUCTION}

Third and fourth degree tears that involve the obstetric anal sphincter complex are also known as obstetric anal sphincter injury (OASI).

A third-degree perineal tear is defined as a partial or complete disruption of the anal sphincter muscles involving either or both external and internal anal sphincter muscles. Depending on the extent of involvement of the muscles the third-degree tear is further subclassified into 3A, 3B and 3C. A fourth degree tear is defined as a third-degree tear that extended to involve anal mucosa.

An isolated anal or rectal injury (button hole tear) is rare and should be documented as separate entity. ${ }^{1}$ The main risk with such injury is the potential of ano or 
rectovaginal fistulae if not recognised and repaired at the time. Currently $3-5 \%$ of women who undergo a vaginal delivery experience an OASI. ${ }^{2}$

OASIS have a significant short and longterm impact on womens quality of life. One of the immediate complications of perineal injury is perineal pain. Shortterm perineal pain is associated with edema and bruising, infection, or wound breakdown.

Perineal pain can lead to urinary retention and defecation problems in the immediate postpartum period. The longterm complications are perineal pain, dyspareunia, abscess formation, wound breakdown, and rectovaginal fistulae. ${ }^{3}$

Obstetrical sphincter injuries have long-term complications of which anal incontinence is the most distressing and disabling. Anal incontinence symptoms are flatal incontinence, passive soiling, incontinence of liquid or solid stool. ${ }^{4}$

Faecal urgency may also be seen in many women. These symptoms are a hygienic, social, and psychological problem for the women. Women does not always forthcome with symptoms of anal incontinence either due to embarrassment or they feel that the symptoms are as a result of normal vaginal delivery. ${ }^{3}$

\section{METHODS}

After obtaining institutional ethical committee clearance, we did a retrospective descriptive study OASIS from the labour case records. The study period was from August 2016 - July 2017. OASIS were classified based on the RCOG guidelines.

\section{Inclusion criteria}

- Singleton pregnancy

- Vertex presentation

- Instrumental

- Normal vaginal delivery.

\section{Exclusion criteria}

- Multiple pregnancy

- Non-vertex presentation

- Caesarean section.

Proforma was developed to capture the age, parity, gestational age in weeks, induction of labour, epidural analgesia, delivery duration, type of episiotomy, instrumentation, shoulder dystocia, occipito posterior position, manual support, weight of the baby, suturing etc. Postnatal evaluation after 6 weeks, 6 months for perineal discomfort, pain, incontinence, wound infection, breakdown, fistula were studied.

\section{Statistical analysis}

Numerical variables were expressed as mean and standard deviation and categorical variables were expressed as frequency and percentages.

\section{RESULTS}

Among the 1573 deliveries, 740 were vaginal birth. Incidence of OASIS was $1.4 \% .81 .8 \%$ (9) women had $3^{\text {rd }}$ degree perineal tear and $18.1 \%(2)$ had $4^{\text {th }}$ degree perineal tear (Figure 1).

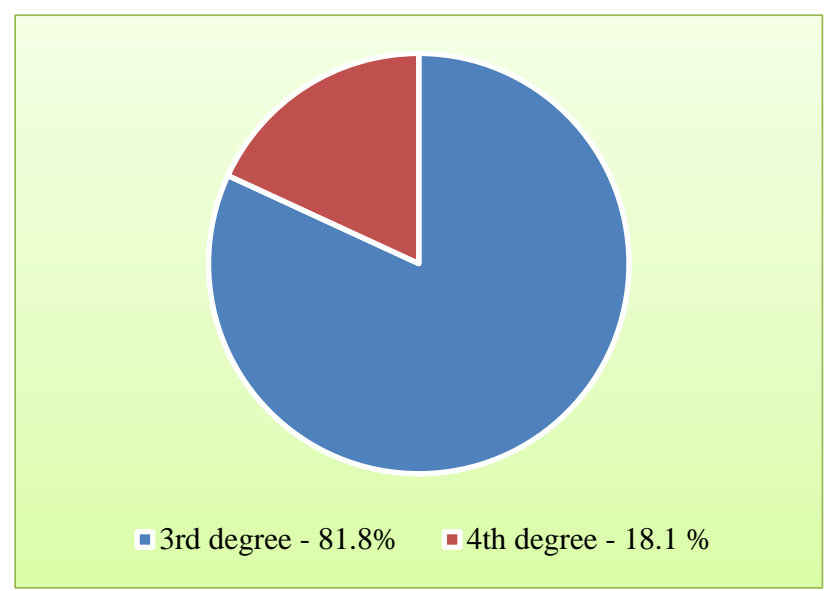

Figure 1: Percentage of $3^{\text {rd }}$ degree versus $4^{\text {th }}$ degree perineal tear.

The mean age of the patients were 27.9 years and gestational age were 39.45 weeks. $72.7 \%$ (8) were nullipara, $27.7 \%$ (3) were multiparous women (Figure 2).

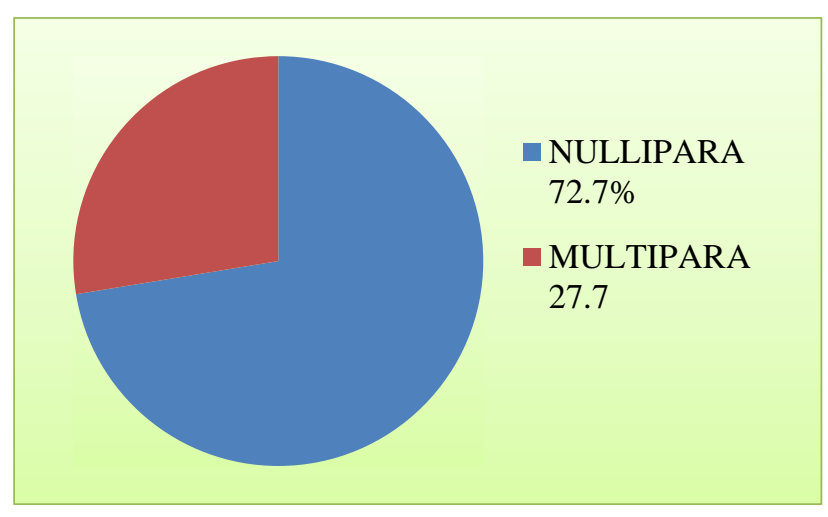

Figure 2: Parity index in OASIS.

Induction of labour with prostaglandins was done in 4 patients $(36.36 \%)$ and pitocin augmentation for 9 patients (81.81\%). $54.54 \%(6)$ out of 11 had epidural labour analgesia. $18.18 \%$ (2) had duration of second stage $<30$ min, $18.18 \%(2)$ had duration $30-59 \mathrm{~min}, 36.36 \%(4)$ had 60-89 min and $27.27 \%$ (3) had duration more than $90 \mathrm{~min}$ (Figure 3). 


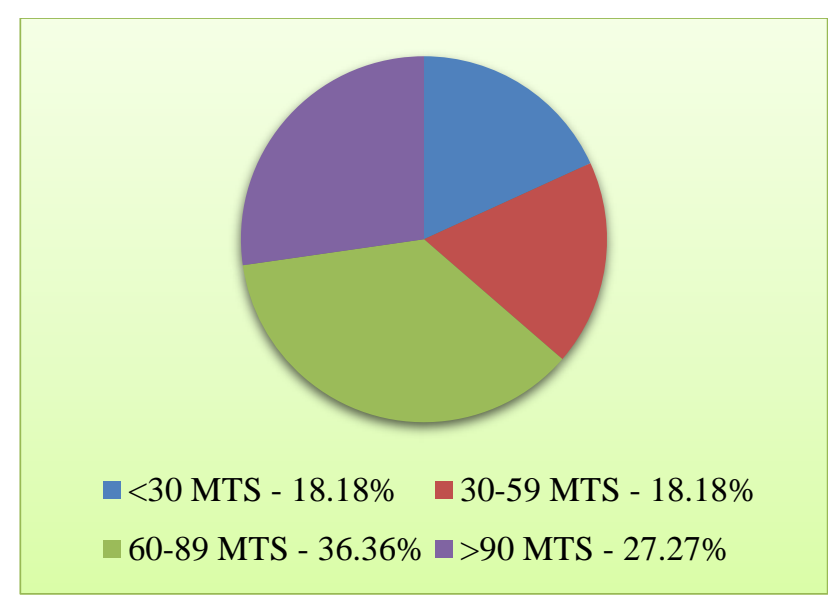

Figure 3: Duration of second stage in OASIS.

Mediolateral episiotomy and manual perineal protection was also given to all vaginal delieveries.36.36\% (4) had instrumental delivery. 36\% (4) had shoulder dystocia.

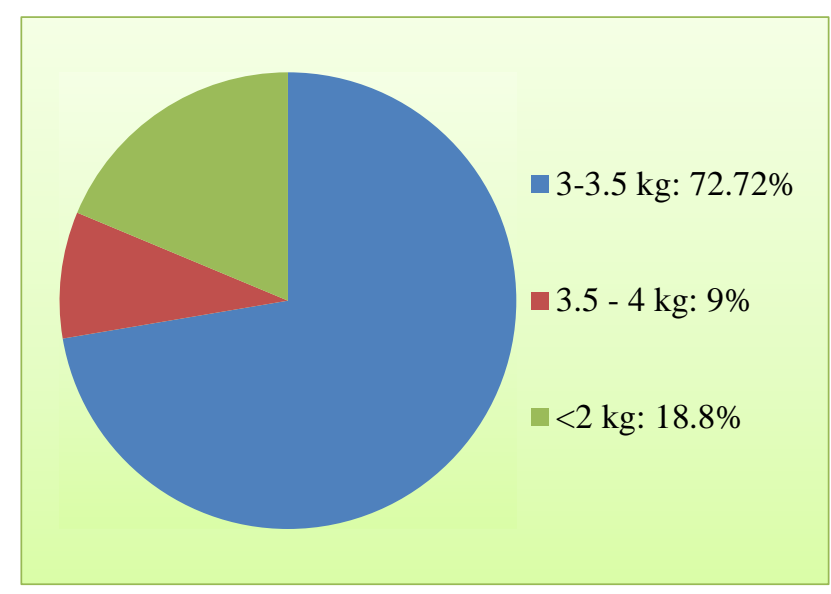

Figure 4: Birth weight of babies in OASIS.

$72.72 \%$ (8) babies had birth weight between $3-3.5 \mathrm{~kg}, 9 \%$ (1) had between $3.5-4 \mathrm{~kg}$ and $18.8 \%$ (2) had weight less than $2 \mathrm{~kg}$ (Figure 4).

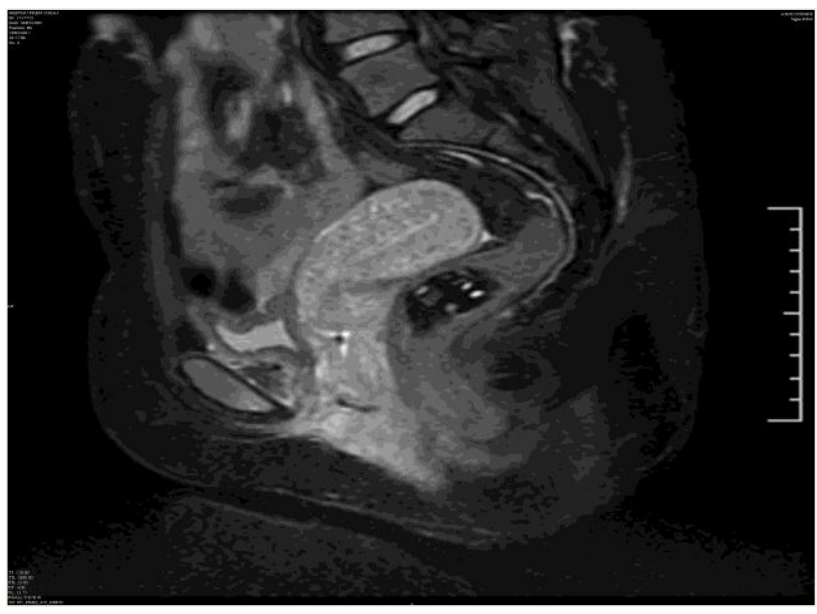

Figure 5: MRI showing Ano vaginal fistula.
Primary suturing was done in all 11 patients. 9\%(1) developed ano vaginal fistula (Figure 5).

\section{DISCUSSION}

Incidence of OASIS was $1.4 \%$ in the present study. Among the vaginal deliveries with mediolateral episiotomy, $0.6 \%$ to $9.0 \%$ sustain obstetric anal sphincter injuries (OASIS). ${ }^{5}$ Prevalence of $3^{\text {rd }}$ and $4^{\text {th }}$ degree perineal tear reported in another study is ranging from 0.1 and $10.29 \%{ }^{6}$

The mean age was 27.9 years and gestational age of the patients was 39.45 weeks. Maternal mean age was 29.9 years in Sara s et al study. ${ }^{7}$ Maternal age, body mass index, position of birth, pool birth,vaginal birth after caesarean section were not found to be independent risk factors in causing OASI. ${ }^{8}$

Out of the 11 patients with OASIS, $8(72.7 \%)$ were nulliparous. Nulliparity has been associated with an increased risk for OASI in other studies. ${ }^{6,9,10}$

Dua et al demonstrated equal perineal length in Caucasian and Asian women in the first stage of labour. They found shorter perineum as an independent risk factor. The perineal length was an independent factor rather than ethnicity, which increased the incidence of OASI in their study. ${ }^{11}$

Induction of labour with PG's was done in 4 patients $(36.36 \%)$ and pitocin augmentation for 9 patients $(81.81 \%)$. The incidence was high with pitocin augmentation. Out of 11 patients $6(54.54 \%)$ had epidural analgesia. Induced and augmented labour were found to be independent risk factors in causing OASIS. Epidural analgesia appears to be a risk factor, on multivariate analysis after adjusting for the instrumental delivery, episiotomy and primigravidity, this appears to be a protective. ${ }^{12}$ Longer duration of second stage of labour and occipito posterior position also increases the risk of OASIS. ${ }^{13}$

$36.36 \%$ had $60-89$ min and $27.27 \%$ had duration more than 90 min in the present study. Studies have shown that when the duration of pushing $>60$ minutes are more to have OASIS. Garmi et al reported for every 1-hour increase in the length of the second stage, the odds for OASIs increased 1.5 times. $^{14}$ The risk of oasis is increased with prolonged second stage and in occipito posterior position. ${ }^{13}$

Mediolateral episiotomy was given to all our patients with $1.5 \%$ of OASIS. With mediolateral episiotomy, $0.6 \%$ to $9.0 \%$ of women had anal sphincter injuries. ${ }^{15}$ Few studies have proven a wider angle of episiotomy may prevent an anal sphincter injury where as a narrow angle would predispose OASI. ${ }^{16,17}$ 
There is a $75 \%$ reduced risk of obstetric anal injuries for each 5.5-mm increase in the length of the episiotomy, and there is an increased risk of sustaining such an injury when the angle is either $<15$ or $>60 .^{18}$

Manual perineal protection was given to all delieveries. Incorporating manual perineal protection at the crowning of fetal head had decreased the incidence of OASIS. ${ }^{19,20}$

Among 11, 36.36\% were delivered by instrumental (forceps: 2 and vacuum: 2). The main risk factor of forceps delivery with a risk of $7 \%$ and $4 \%$ in each of primiparity, shoulder dystocia and prolonged second stage. ${ }^{21}$ Vasileios et al found that the incidence is high whether it was forceps or vacuum delivery. ${ }^{8}$

$72.72 \%$ babies had birth weight between $3-3.5 \mathrm{~kg}$, (9\%) had between 3.5-4 kg. Groutz et al reported an independent risk factor for perineal tears was birthweight $\geq 4000$ g. ${ }^{13}$ Larger birth weight results in a larger head circumference, prolonged labour, a higher risk of instrumental delivery and shoulder dystocia. ${ }^{22,23}$ OASIS disrupt the supports of the pelvic floor as well as increase the risk for pudendal neuropathy which result in functional bowel problems. ${ }^{24}$

Primary suturing was done by trained gynaecologist. Technique of suturing were different for different surgeons. Suturing was done operating theatre only for one patient who had $4^{\text {th }}$ degree perineal tear. Others underwent suturing in labour room. In all the cases, suturing was done by polyglactin (Vicryl). The method of suturing was not mentioned in case records.

Repair in an operating theatre will allow the repair to be performed under optimal conditions with appropriate instruments, adequate light and an assistant. Regional or general anaesthesia will facilitate identification of the full extent of the injury and enable retrieval of the retracted ends of the torn anal sphincter. ${ }^{25}$

A randomized trial by Williams et al, compared OASIS repairs with polyglactin (Vicryl) and polydioxanone (PDS). They found no significant difference in suturerelated morbidity at 6 weeks. ${ }^{26}$

Cochrane review in 2013 found a statistically significant lower incidence of faecal urgency, anal incontinence scores and anal incontinence symptoms at 12 months in the overlap group. But at the end of 36 months there was no significant differences in flatus or faecal incontinence between the two groups. ${ }^{27}$

All patients received antibiotic for 5 days and was started on laxatives in postoperative period. The use of broadspectrum antibiotics is recommended following repair of OASIS to reduce the risk of postoperative infections and wound dehiscence. The use of postoperative laxatives is recommended by RCOG to reduce the risk of wound dehiscence. $^{28}$
All the patients were followed in OPD after 6 weeks. Out of these, $1(9 \%)$ patient developed anovaginal fistula. She presented as unable to hold flatus, passing flatus through vagina, fecal soiling and perineal pain within 4 weeks of delivery. It was an anovaginal fistula, in the midline 1.5 $\mathrm{cm}$ from the anal verge. She underwent laparoscopic temporary end sigmoid colostomy. Anal sphincter repair with pedicled flap cover was done 3 months later. She developed wound infection after the repair.

Misdiagnosis of tears, poor repair technique, or inadequate postoperative management may all contribute to poor outcomes. ${ }^{29} \mathrm{~A}$ failed repair was considered when there was wound dehiscence, sphincter disruption, rectovaginalfistula, and or faecal incontinence. Three patients experienced a repair failure (1 RVF) in a study. ${ }^{13}$ If the tear involves the rectal mucosa with an intact anal sphincter complex, it is by definition not a fourth-degree tear. This has to be documented as a rectal buttonhole tear. If not recognised and repaired, this type of tear may lead to a rectovaginal fistula. ${ }^{25}$ An increasing incidence of third- or fourth-degree perineal tears does not necessarily indicate poor quality care. But it may rather indicate an improved quality of care through better detection and reporting. ${ }^{30}$

This was a retrospective study. Hence, we could not find out the angle of episiotomy, length of perineum and suturing method as documented by other studies.

\section{CONCLUSION}

OASIS is un preventable in vaginal deliveries due to the multifactorial risk factors. The outcome of perineal injuries is often unpredictable. The long-term morbidity of OASIS such as anal incontinence and fistula can lead to social, emotional, physical and marital problems. The financial constraints are yet another distressing part of it. Precautions to reduce the incidence by proper training, identification of cases and appropriate management has to emphasised.

\section{Funding: No funding sources \\ Conflict of interest: None declared}

Ethical approval: The study was approved by the Institutional Ethics Committee

\section{REFERENCES}

1. Sultan AH, Thakar R. Lower genital tract and anal sphincter trauma. Best Pract Res Clin Obstet Gynaecol. 2002;16(1):99-115.

2. Friedman AM, Ananth CV, Predergast ED, Alton ME, Wright JD. Evaluation of third-degree and fourthdegree laceration rates as quality indicators. Obstet Gynecol. 2015;125:927-37.

3. Harvey M, Kingston ON, Pierce M, Halifax NS. Obstetrical Anal Sphincter Injuries (OASIS): prevention, recognition, and repair. J Obstet Gynaecol Can. 2015;37(12):1131-48. 
4. Haylen BT, de Ridder D, Freeman RM, Swift SE, Berghmans $\mathrm{B}$, Lee $\mathrm{J}$, et al. An International Urogynecological Association (IUGA)/International Continence Society (ICS) joint report on the terminologyfor female pelvic floor dysfunction. Neurourol Urodyn. 2010;29:4-20

5. Thacher SB, Banta HD. Benefits and risks of episiotomy: an interpretative review of the English language literature, 1860-1980. Obstet Gynecol Sur. 1983;38:322-38.

6. Hirayama F, Koyanagi A, Mori R, Zhang J, Souza JP, Gülmezoglu AM. Prevalence and risk factors for thirdand fourth-degree perineal lacerations during vaginal delivery: a multi-country study. Inter J Obste Gynaecol. 2012;119(3):340-7.

7. Webb SS, Hemming K, Khalfaoui MY, Henriksen TB, Kindberg S, Stensgaard S, et al. An obstetric sphincter injury risk identification system (OSIRIS): is this a clinically useful tool? Int Urogynecol J. 2017;28(3):367-74.

8. Pergialiotis V, Vlachos D, Protopapas A, Pappa K, Vlachos G. Risk factors for severe perineal lacerations during childbirth. Int J Gynecol Obstet. 2014;125(1):614.4

9. Groutz A, Hasson J, Wengier A. Third- and fourthdegree perineal tears: prevalence and risk factors in the third millennium. Am J Obstet Gynecol 2011;204:347.e1-4.

10. Stedenfeldt M, Øian P, Gissler M, Blix E, Pirhonen J. Risk factors for obstetric anal sphincter injury after a successful multicentre interventional programme. BJOG. 2014;121(1):83-91.

11. Dua A, Whitworth M, Dugdale A, Hill S. Perineal length: norms in gravid women in the first stage of labour. Int Urogynecol J Pelvic Floor Dysfunct. 2009;20(11):1361-4.

12. de Vogel J, van der Leeuw-van Beek A, Gietelink D, Vujkovic M, de Leeuw JW, van Bavel J, et al. The effect of a mediolateral episiotomy during operative vaginal delivery on the risk of developing obstetrical anal sphincter injuries. Am J Obstet Gynecol. 2012;206(5):404.e1-5.

13. Cawich SO, Wright D, Kulkarni S, Rattray C, Bambury I, Christie L, et al. Severe perineal lacerations in obstetric practice: the effect of institutional practice guidelines on repair failures in a single centre. Int Scholarly Research Notices. 2014:131682.

14. Garmi G, Peretz H, Braverman M, Berkovich I, Molnar R, Salim R. Risk factors for obstetric anal sphincter injury: to prolong or to vacuum? Midwifery. 2016;34:178-82.

15. Karbanova J, Rusavy Z, Betincova L, Jansova M, Parizek A, Kalis V. Clinical evaluation of peripartum outcomes of mediolateral versus lateral episiotomy. Int J Gynecol Obstet. 2014;124(1):72-6.

16. Kalis V, Karbanova J, Horak M, Lobovsky L, Kralickova M, Rokyta Z. The incision angle of mediolateral episiotomy before delivery and after repair. Int J Gynecol Obstet. 2008;103(1):5-8.

17. Stedenfeldt M, Pirhonen J, Blix E, Wilsgaard T, Vonen B, Øian P. Episiotomy characteristics and risks for obstetric anal sphincter injuries: a case-control study. BJOG. 2012;119:724-30.

18. Naidu M, Sultan AH, Thakar R. Reducing obstetric anal sphincter injuries using perineal support: our preliminary experience. Int Urogynecol J. 2017;28:3819.

19. Leenskjold S, Hoj L, Pirhonen J. Manual protection of the perineum reduces the risk of obstetric anal sphincter ruptures. Dan Med J. 2015;62(5).

20. Christianson LM, Bovbjerg VE, McDavitt EC, Hullfish KL. Risk factors for perineal injury during delivery. Am J Obstet Gynecol. 2003;189(1):255-60.

21. Richter HE, Brumfield CG, Cliver SP, Burgio KL, Neely CL, Varner RE. Risk factors associated with anal sphincter tear: a comparison of primiparous patients, vaginal births after caesarean deliveries, and patients with previous vaginal delivery. Am J Obstet Gynecol. 2002;187(5):1194-8.

22. Hudelist G, Gelle'n J, Singer C, Ruecklinger E, Czerwenka $\mathrm{K}$, Kandolf $\mathrm{O}$, et al. Factors predicting severe perineal trauma during childbirth: role of forceps delivery routinely combined with mediolateral episiotomy. Am J Obstet Gynecol. 2005;192(3):875-81.

23. Fernando RJ. Risk factors and management of obstetric perineal injury. Obstet Gynaecol Reprod Med. 2007;17(8):238-43.

24. Sultan AH, Kettle C. Diagnosis of perineal trauma. In: Sultan AH, Thakar R, Fenner DE, eds. Perineal and anal sphincter trauma. London: Springer; 2007:13-9.

25. Williams A, Adams EJ, Tincello DG, Alfirevic Z, Walkinshaw SA, Richmond DH. How to repair an anal sphincter injury after vaginal delivery: results of a randomised controlled trial. BJOG. 2006;113:201-7.

26. Fernando R, Sultan AH, Kettle C, Thakar R, Radley S. Methods of repair for obstetric anal sphincter injury. Cochrane Database Syst Rev. 2013;(3):CD002866

27. Royal College of Obstetricians and Gynaecologists. A third- or fourth-degree tear during birth: information for you. London: RCOG; 2015.

28. Thakar R, Sultan AH, Fernando R, Monga A, Stanton S. Can workshops on obstetric anal sphincter rupture change practice? Int Urogynecol J. 2001;12(3):S5.

29. Baghurst PA. The case for retaining severe perineal tears as an indicator of the quality of obstetric care. Aust N Z J Obstet Gynaecol. 2013;53:3-8.

Cite this article as: Soman S, Nair SS, Janani JN, Radhamany K, Kurien AJ. OASIS: clinical audit in a tertiary care centre. Int J Reprod Contracept Obstet Gynecol 2018;7:1958-62. 